\title{
Removal of Fluoride and Hardness in Dietary Intake (water) in Chronic Kidney Disease of unknown Etiology (CKDu) Prevalent Areas by Domestic Reverse Osmosis Units
}

\author{
S.M. Imbulana, W.B. Gunawardana, M.W. Jayaweera, J.M.A. Manatunge ${ }^{*}$, A.A.S.U. \\ Gunarathna, M.I. Sudasinghe \\ Department of Civil Engineering, University of Moratuwa, Sri Lanka \\ *manatunge@gmail.com
}

\begin{abstract}
The origin of Chronic Kidney Disease of unknown etiology ( $\mathrm{CKDu}$ ) that is rapidly invading the dry zone of Sri Lanka has not yet been identified. However, occurrence of the disease is thought to be linked with excess levels of fluoride and hardness in drinking water. Hence, the study herein focuses to evaluate the suitability of domestic Reverse Osmosis (RO) units; which introduced in $\mathrm{CKDu}$ affected areas to remove excess fluoride and hardness. Accordingly, the drinking water quality in CKDu prevalent areas in terms of fluoride and hardness was simulated in the laboratory and the removal of aforesaid constituents using domestic ROs was investigated.
\end{abstract}

According to water quality analyses, domestic $\mathrm{RO}$ units effectively removed hardness even at extremely high initial concentrations, such as $1,730 \mathrm{mg} / \mathrm{L}$ (as $\mathrm{CaCO}_{3}$ ). Excessive removal of Calcium and Magnesium by the RO units was observed, thus remineralization of the permeate up to $80-100 \mathrm{mg} / \mathrm{L}$ as $\mathrm{CaCO}_{3}$ is required to ensure health benefits. Meanwhile, fluoride removal was observed to be highly dependent upon initial fluoride and hardness concentrations. It was not possible to suggest an 'optimum removal level' for fluoride, where permeate fluoride concentration exceeded the maximum permissible WHO Drinking Water Guideline value of $1.5 \mathrm{mg} / \mathrm{L}$. However, it may arise at a point where fluoride and hardness concentrations in raw water fall within $1.7-3.5 \mathrm{mg} / \mathrm{L}$ and $570-1,130 \mathrm{mg} / \mathrm{L}$ as $\mathrm{CaCO}_{3}$, respectively.

Plausible reasons for ineffective removal of fluoride could be the relatively small size and low ionic charge of fluoride. Additionally, high concentration of heavy ions may interfere with fluoride adsorption of activated carbon filter in the domestic RO unit. Effective fluoride removal could be achieved by adopting appropriate pre-treatment methods for hardness removal. Separate threshold levels for fluoride and hardness levels in drinking water should be defined, especially for CKDu patients.

Keywords: Chronic Kidney Disease, Domestic reverse osmosis units, Fluoride, Hardness 